\title{
PWM-Based Sliding Mode Controller for Three-Level Full-Bridge DC-DC Converter that Eliminates Static Output Voltage Error
}

\author{
Jilong Liu ${ }^{\dagger}$, Fei Xiao*, Weiming Ma*, Xuexin Fan*, and Wei Chen ${ }^{*}$ \\ 'School of Electrical Engineering, Xi'an Jiaotong University, Xi'an, China \\ *National Key Laboratory of Science and Technology on Vessel Integrated Power System, Naval University of \\ Engineering, Wuhan, China
}

\begin{abstract}
This paper proposes a pulse width modulation (PWM)-based sliding mode controller (SMC) for a full-bridge DC-DC converter that can eliminate static output voltage error. Hysteretic SMC in DC-DC converter does not have a fixed switching frequency, and applying hysteretic SMC to full-bridge converters is difficult. Fixed-frequency SMC, which is also called PWM-based SMC, based on equivalent control overcomes these shortcomings. However, the controller order reduction in equivalent control in PWM-based SMC causes static output voltage error. To resolve this issue, an integral item is added to the PWM-based SMC. Sliding mode coefficients are designed by applying a standard second-order system to the sliding mode surface. The effect of adding an integral item on the controller is analyzed, and an integral coefficient design method is proposed. Experiment results on a three-level full-bridge DC-DC converter verify the control scheme and design method proposed in this paper.
\end{abstract}

Key words: Additional integral item, PWM sliding mode control, Sliding mode coefficients, Static output voltage error, Three-level converter

\section{INTRODUCTION}

Traditional linear PI controller is based on a small signal model, which is only effective in a very narrow range. Although the PI control scheme is widely used, it shows limited performance, especially poor robustness against parameter uncertainties. Thus, this scheme is unsuitable for variable structure systems [1], [2]. Sliding mode controller (SMC) is a kind of nonlinear controller suitable for variable structure systems. This controller can guarantee stability and robustness against parameter uncertainties. Infinite frequency is the ideal operating frequency of SMC. However, switching frequencies of power converters must be restricted within a practical range [3]-[5].

Hysteretic SMC requires a bang-bang type of controller and has variable switching frequencies. Switching frequency is

Manuscript received Aug. 3, 2014; accepted Oct. 18, 2014

Recommended for publication by Associate Editor Shihua Li.

${ }^{\dagger}$ Corresponding Author: 66976@163.com

Tel: +86-27-83648171, Fax: +86-27-83648171, Xi'an Jiaotong Univ.

*National Key Laboratory of Science and Technology on Vessel Integrated Power System, Naval University of Engineering, China affected by input voltage and load. Variable switching frequencies challenge the feasibility of hysteretic SMC because the filter must suit a wide frequency range. Moreover, hysteretic SMC can only be used in simple DC-DC converters such as buck and boost. Hysteretic SMC cannot be directly used in full-bridge converters [6], [7]. The converters proposed in [8], [9] require control variables, such as duty cycle and phase-shift angle. If SMC is used in the converters in [8] and [9], then the equivalent control variable can be derived.

Equivalent control concept is introduced into the SMC to obtain the fixed-frequency control scheme. Fixed-frequency SMC, also called pulse width modulation (PWM)-based SMC, can resolve the problems of hysteretic SMC. The PWM technique can be used in SMC. The duty cycle control variable is independent from the switching frequency. Thus, the application of the PWM technique to SMC does not contradict the concept of classical PWM controllers used in power electronics. SMC is based on SMC law, whereas classical PWM control is based on linear control law [10]. PWM technique gives SMC the ability to be used in a wide range of DC-DC converters [10]-[12]. In [11], [12], the sling mode 


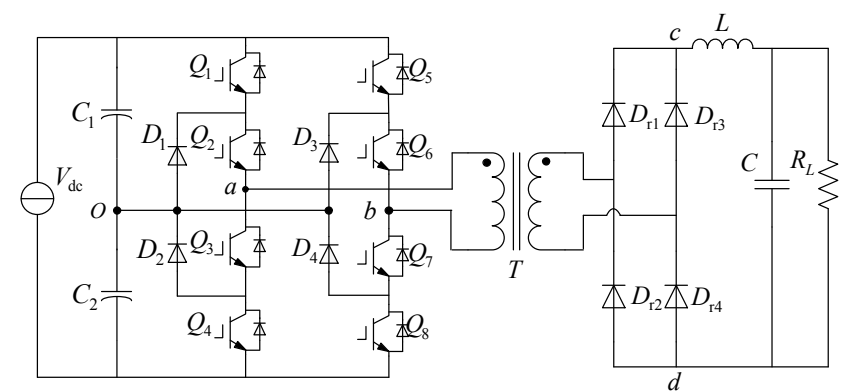

Fig. 1. Three-level full-bridge DC-DC converter.

coefficients are analyzed and the design method is introduced.

An SMC with double integral sliding surface for buck converter is designed in [13]. In [13], the SMC is analyzed and designed as a third-order system. Meanwhile, in the present paper, the second-order sliding surface and the additional integral are analyzed and designed, respectively. In [14] a sampled-data reduced-order observer is adopted to deal with the unknown parameters, and a robust sampled-data output feedback control law developed to achieve global tracking control performance in high precision for buck converter.

In [15], SMC scheme via multi-resonant sliding surface is used for single-phase grid-connected voltage source inverter. In [16], active damping based on SMC is used in three-phase voltage inverters. Sliding mode observer is used in sensor-less vector control of induction machine in [17]. The SMC strategy is applied to a permanent magnet synchronous machine vector control system in [18] to improve system robustness amid parameter changes and disturbances.

SMC with a fast output sampling strategy is used in [19] for an uncertain system to avoid switching of control and chattering. A new development in the time optimal control theory in SMC systems for multi-quadrant buck converters with a variable load is presented in [20]. In [21] and [22], the analysis and design of parallel-connected converter system using SMC techniques are proposed. In [23], a complete SMC scheme is designed for the voltage tracking control of a conventional boost converter. A robust adaptive SMC is designed for a boost converter in [24]. An active anti-disturbance control approach called disturbance observer-based control is analyzed in [25]. This controller provides an active and effective way to handle disturbances and improve robustness of the closed-loop system. An SMC approach for systems with mismatched uncertainties via a nonlinear disturbance observer is developed in [26].

However, equivalent control scheme reduces the order of the SMC. Traditional PWM-based SMC has no ability to eliminate static output voltage error, which is influenced by the load. In the present paper, the integral of output voltage error is added to the SMC as a new control item. Sliding mode coefficients are designed by applying a standard second-order system to the sliding mode surface. The effect of adding an integral item on the controller is analyzed, and an integral coefficient design method is proposed.

This paper is organized as follows. The three-level full-bridge converter and its phase-shift control scheme are introduced in Section II. Traditional PWM-based SMC is introduced in Section III. PWM-based SMC with an additional integral to eliminate static output voltage error is proposed in Section IV. Sliding mode coefficients and an additional integral coefficient are designed in Section V. Experiment results are given in Section VI, and the conclusion is presented in Section VII.

\section{THREE-LEVEL FULL-BRIDGE CONVERTER AND ITS PHASE-SHIFT CONTROL SCHEME}

The structure of neutral-point-clamped (NPC) three-level full-bridge converter is shown in Fig. 1. The converter includes two NPC three-level bridges. The center tap of the two capacitors provides neutral voltage for the converter. Each phase leg of the three-level converter has two pairs of switching devices in series. The center of each device pair is clamped to the neutral through a clamping diode. In this kind of converter, the voltage stress of main switches is half of the input voltage by using the NPC technique. This structure is suitable for high-voltage and high-power applications [27].

The converter has a high-frequency transformer and an uncontrolled rectifier bridge (Fig. 1). Inductor $L$ and capacitor $C$ comprise the low-pass $L C$ filter. Resistor $R_{\mathrm{L}}$ is the load of the converter. Compared with a two-level full-bridge converter, this converter has more switches and its phase-shift control scheme is more complex.

One of the most useful phase-shift control schemes is shown in Fig. 2. Switches $Q 1$ to $Q 4$ are all switched out of phase. The right leg is similar to the left leg. Both voltages $u_{\text {ao }}$ and $u_{\text {bo }}$ have three levels. The primary side voltage of the transformer $u_{\mathrm{ab}}$ has five levels. In this converter, the main two control variables are conduction angle $\theta$ and phase-shift angle $\alpha$. In Fig. 2, $\gamma$ is the clamp angle and is shown in Equation (1). Hysteretic SMC cannot be directly used in a three-level full-bridge converter (Figs. 1 and 2).

$$
\gamma=\pi-\theta
$$

THD of the primary side voltage of the transformer should be kept low because voltage and current harmonics will result in high power loss and excessive temperature rise, which will eventually diminish the useful life of the transformer. Figure 3 shows the primary side voltage of the transformer in one switching period. The converter switching frequency must be selected as the fundamental frequency, and the THD of the waveforms in Fig. 3 must be analyzed.

THD of the waveforms is shown in Equation (2) and determined by conduction angle and phase-shift angle. These two control variables should be selected to keep the THD low, and thus find the optimal operation point. The minimum value of the THD can be searched using a mathematical tool. 


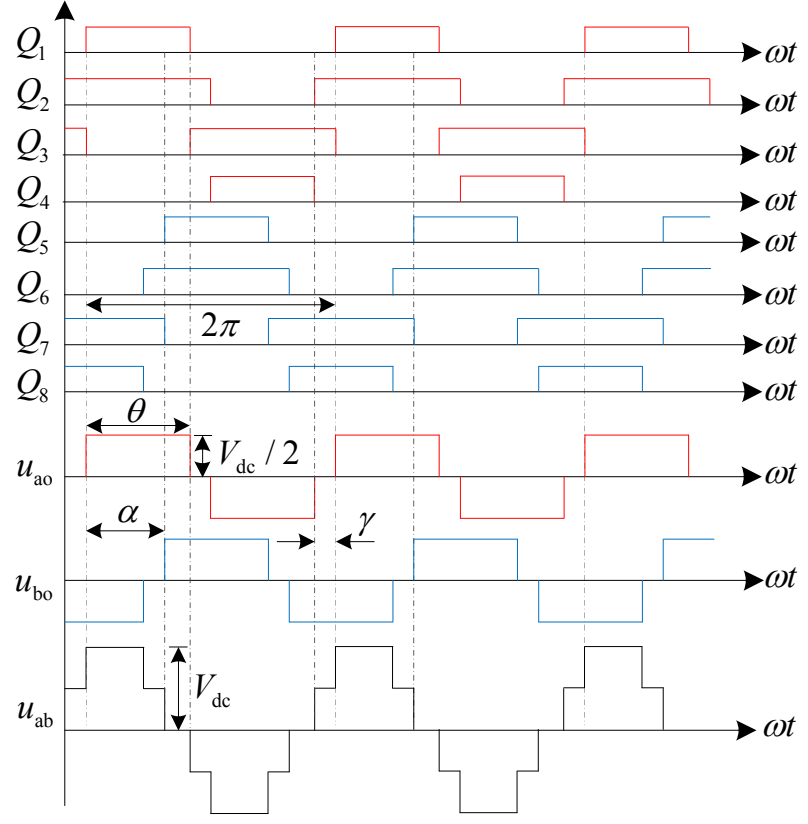

Fig. 2. Phase-shift control of three-level full-bridge converter.

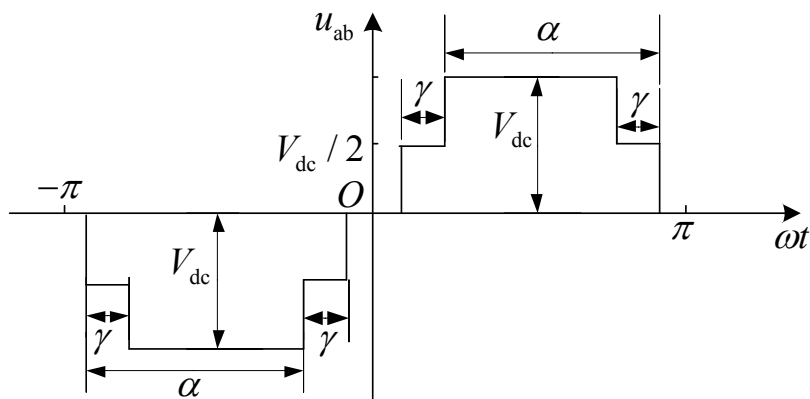

Fig. 3. Primary side voltage of the transformer in one switching period.

On the optimal operation point, the conduction angle value is $2.636 \mathrm{rad}$ and the phase-shift angle value is $2.187 \mathrm{rad}$.

Phase-shift angle and conduction angle influence the fundamental output voltage. After the optimal operation point is selected, the transformer ratio will be designed according to the operation point and the desired output voltage. The phase-shift angle will then be close to the optimal operation point when the converter is working.

$$
\begin{gathered}
T H D=\sqrt{\frac{\pi(2 \alpha-\pi+\theta)}{16 \sin ^{2}\left(\frac{\theta}{2}\right) \sin ^{2}\left(\frac{\alpha}{2}\right)}-1} \\
d=\frac{\alpha}{\pi}
\end{gathered}
$$

Conduction angle should be initialized when the converter is started. The phase-shift angle is generated by the SMC. Duty cycle control value is obtained from the PWM-based SMC. The relationship between duty cycle value and phase-shift angle is shown in Equation (3).

From this section, the hysteretic SMC cannot be used directly in the three-level full-bridge converter. In a buck converter, the only switch can be driven with a bang-bang type controller. Meanwhile, in full-bridge converter, basic SMC based on a mathematical model cannot be directly used. Thus, the equivalent SMC should be derived.

\section{PWM-BASED SMC}

As described in Section I, hysteretic SMC cannot be directly used in a full-bridge converter. However, PWM-based SMC should be obtained from the hysteretic SMC model. In this section, hysteretic SMC will be initially derived, and then the PWM-based SMC will be obtained by applying the equivalent control concept.

\section{A. Hysteretic SMC}

Fig. 4 shows the hysteretic SMC. The control function $u$ is 0 or 1 (Fig. 4). This control function can be used in a buck or boost converter. Equivalent control function should be obtained from control function $u$. Three variables are selected as the state variables for the hysteretic SMC (Fig. 4), namely, output voltage error $x_{1}$, differential of output voltage error $x_{2}$, and integral of output voltage error $x_{3}$. These variables are defined as Equation (5).

A new variable $v_{\mathrm{i}}$ is introduced to simplify the analysis, as shown in Equation (4). This variable is defined through input voltage and ratio of isolated transformer from primary side to secondary side.

$$
v_{\mathrm{i}}=V_{\mathrm{dc}} / n_{\mathrm{T}}
$$

State space variable vector is defined as Equation (5), and the system model of three-level full-bridge DC-DC converter is applied.

From Equation (5), the state space function of hysteretic SMC can be obtained, as shown in Equation (6). The three matrixes are coefficients of state space function.

$$
\begin{aligned}
& \boldsymbol{x}=\left[\begin{array}{l}
x_{1} \\
x_{2} \\
x_{3}
\end{array}\right]=\left[\begin{array}{l}
V_{\text {ref }}-v_{\mathrm{o}} \\
\frac{\mathrm{d}\left(V_{\text {ref }}-v_{\mathrm{o}}\right)}{\mathrm{d} t} \\
\int\left(V_{\text {ref }}-v_{\mathrm{o}}\right) \mathrm{d} t
\end{array}\right]=\left[\begin{array}{l}
V_{\text {ref }}-v_{\mathrm{o}} \\
\frac{v_{\mathrm{o}}}{R_{\mathrm{L}} C}+\int \frac{\left(v_{\mathrm{o}}-v_{\mathrm{i}} u\right)}{L C} \mathrm{~d} t \\
\int x_{1} \mathrm{~d} t
\end{array}\right] \\
& \dot{\boldsymbol{x}}=\boldsymbol{A} \boldsymbol{x}+\boldsymbol{B} u+\boldsymbol{D}
\end{aligned}
$$

where

$$
\boldsymbol{A}=\left[\begin{array}{ccc}
0 & 1 & 0 \\
0 & -\frac{1}{R_{\mathrm{L} C}} & 0 \\
1 & 0 & 0
\end{array}\right] \quad \boldsymbol{B}=\left[\begin{array}{c}
0 \\
-\frac{v_{\mathrm{i}}}{L C} \\
0
\end{array}\right] \quad \boldsymbol{D}=\left[\begin{array}{c}
0 \\
\frac{v_{\mathrm{o}}}{L C} \\
0
\end{array}\right]
$$

In the SMC, variable $S$ is defined as an instantaneous trajectory of state variable, as shown in Equation (7). The aim of SMC is to design a certain sliding surface in its control law that will direct the trajectory of state variables toward a desired region. By enforcing $S=0$, a sliding surface can be obtained for the SMC. 


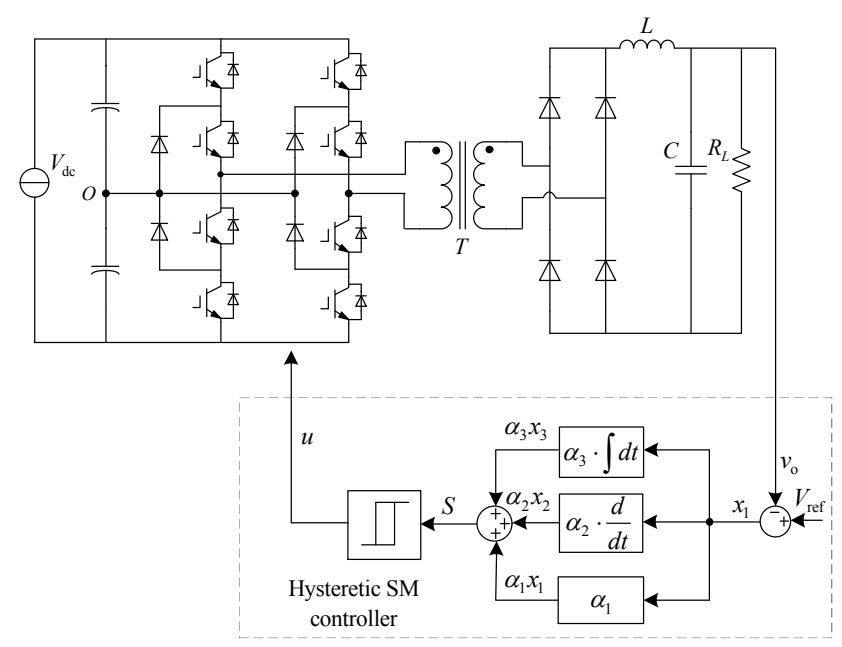

Fig. 4. Hysteretic SMC for DC-DC converter.

$$
S=\alpha_{1} x_{1}+\alpha_{2} x_{2}+\alpha_{3} x_{3}=\boldsymbol{J}^{\mathrm{T}} \boldsymbol{x}
$$

where

$$
\boldsymbol{J}^{\mathrm{T}}=\left[\begin{array}{lll}
\alpha_{1} & \alpha_{2} & \alpha_{3}
\end{array}\right]
$$

In the sliding surface $S=0, \alpha_{1}, \alpha_{2}$, and $\alpha_{3}$ are the sliding mode coefficients to determine the trajectory of state variables. These three coefficients are the main parameters we need to design. A new matrix that represents sliding mode coefficients is defined as Equation (8).

Switching function shown in Equation (9) is adopted as the control law of the SMC. This control law is a bang-bang type control function, and its output is determined by the trajectory of the state variable.

$$
u= \begin{cases}1, & S>0 \\ 0, & S<0\end{cases}
$$

The entire sliding mode movement process can be divided into two stages. In the first stage, the controller forces the trajectory of the state variable to reach the sliding surface. When the trajectory is within a small vicinity of the sliding surface, the trajectory is in sliding mode operation, which is the second stage of the control process. The SMC will give the converter continuous control actions to maintain the trajectory of the state variable within a small vicinity of sliding surface.

\section{B. Existence Condition of SMC}

In all of the SMCs, sliding coefficients should satisfy the existence condition of SMC. Such satisfaction will ensure that the trajectory of the state variable will always be directed toward the sliding surface. The direct method of Lyapunov is adopted in the existence condition analysis of SMC [13]. Time differential of Equation (7) is shown in Equation (10). To achieve the local reachability of SMC, Equation (11) should be satisfied.

$$
\begin{gathered}
\dot{S}=\boldsymbol{J}^{\boldsymbol{T}} \boldsymbol{A} \boldsymbol{x}+\boldsymbol{J}^{\boldsymbol{T}} \boldsymbol{B} u+\boldsymbol{J}^{\boldsymbol{T}} \boldsymbol{D} \\
\lim _{S \rightarrow 0} S \cdot \dot{S}<0
\end{gathered}
$$

Equation (11) can be rewritten as Equation (12).

$$
\left\{\begin{array}{l}
\dot{S}_{S \rightarrow 0^{+}}=\boldsymbol{J}^{\boldsymbol{T}} \boldsymbol{A} \boldsymbol{x}+\boldsymbol{J}^{T} \boldsymbol{B} u_{S \rightarrow 0^{+}}+\boldsymbol{J}^{\boldsymbol{T}} \boldsymbol{D}<0 \\
\dot{S}_{S \rightarrow 0^{-}}=\boldsymbol{J}^{\boldsymbol{T}} \boldsymbol{A} \boldsymbol{x}+\boldsymbol{J}^{T} \boldsymbol{B} u_{S \rightarrow 0^{-}}+\boldsymbol{J}^{T} \boldsymbol{D}>0
\end{array}\right.
$$

Existence condition of SMC can be obtained from Equations (6)-(8), and (12). The detailed condition including sliding coefficients is shown in Equation (13).

$$
0<L\left(\frac{1}{R_{\mathrm{L}} C}-\frac{\alpha_{1}}{\alpha_{2}}\right) i_{\mathrm{C}}+L C \frac{\alpha_{3}}{\alpha_{2}}\left(V_{\text {ref }}-v_{\mathrm{o}}\right)+v_{\mathrm{o}}<v_{\mathrm{i}}
$$

From Equation (13), the input voltage, load resistor, filter inductor, filter capacitor, and output voltage will all influence the existence condition. When designing the sliding coefficients, all these items will be considered.

\section{Equivalent Control of SMC}

If PWM technique can be used in SMC, the switching frequency of the converter will be fixed. The control law will not be a bang-bang type, and the control variable for the converter will become the duty cycle. Notably, PWM technique should not destroy the SMC property. In the SMC, the discrete control input $u$ can be theoretically replaced by a smooth function known as the equivalent control signal $u_{\text {eq }}$. This equivalent control signal can be obtained by force time differentiation of Equation (7) equals zero, as shown in Equation (14).

$$
\dot{S}=J^{T} A \boldsymbol{x}+J^{T} B u_{\text {eq }}+J^{T} D=0
$$

Equivalent control signal is derived as Equations (15) and (16). At high switching frequency, the equivalent control is an effective duty cycle control [4].

$$
\begin{gathered}
d_{\mathrm{eq}}=u_{\mathrm{eq}}=-\left[\boldsymbol{J}^{\boldsymbol{T}} \boldsymbol{B}\right]^{-1} \boldsymbol{J}^{\boldsymbol{T}}[\boldsymbol{A} \boldsymbol{x}+\boldsymbol{D}] \\
d_{\mathrm{eq}}=\frac{L}{v_{\mathrm{i}}}\left(\frac{1}{R_{\mathrm{L}} C}-\frac{\alpha_{1}}{\alpha_{2}}\right) i_{\mathrm{C}}+\frac{\alpha_{3} L C}{\alpha_{2} v_{\mathrm{i}}}\left(V_{\mathrm{ref}}-v_{\mathrm{o}}\right)+\frac{v_{\mathrm{o}}}{v_{\mathrm{i}}}
\end{gathered}
$$

PWM-based SMC for three-level full-bridge DC-DC converter is shown in Fig. 5. In this controller, output voltage and capacitor current should be sampled. The SMC generates the equivalent duty cycle and uses this variable for the full-bridge DC-DC converter.

\section{Static Output Voltage Error}

In the PWM-based SMC, the equivalent control variable does not include the integral item of output voltage error. The second-order hysteretic SMC becomes the first-order PWM-based SMC after equivalent control conversion. The first-order system has the ability to achieve good dynamic performance. However, it has no ability to resist the static output voltage error. Fig. 6 shows the static error of PWM-based SMC under load step up and load step down obtained by simulation. The input voltage of the converter is $1000 \mathrm{Vdc}$. The ratio of the isolated transformer from primary side to secondary side is 2.0. The desired output DC voltage is $330 \mathrm{Vdc}$. In Fig. 6, the load before $0.1 \mathrm{~s}$ and after $0.16 \mathrm{~s}$ is 


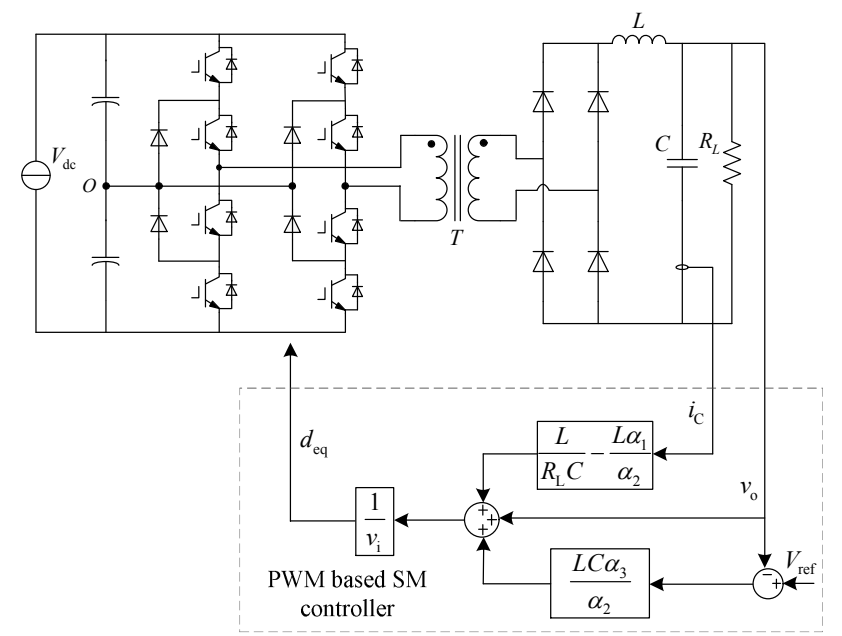

Fig. 5. PWM-based SMC for three-level full-bridge DC-DC converter.

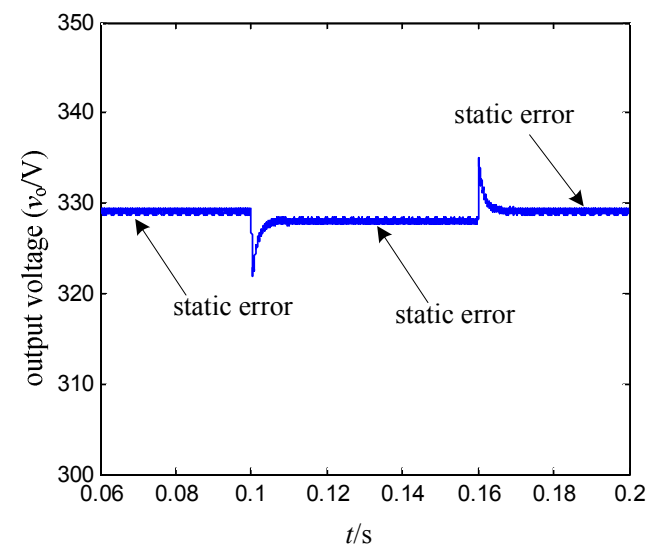

Fig. 6. Static error of PWM-based SMC under load step up and load step down obtained by simulation.

$8 \Omega$, and the load between 0.1 and $0.16 \mathrm{~s}$ is $4 \Omega$. The output current causes voltage drop on the wire, transformer, and inductor. A large output current causes a large voltage drop and a large static output voltage error. The output voltage error cannot be eliminated because there is no integral item in the first order PWM-based SMC.

Adding an integral item to the SMC is an effective and simple method to avoid and/or eliminate static output voltage error. This integral item will be analyzed in the next section.

\section{PWM-BASED SMC WITH ADDITIONAL INTEGRAL}

\section{A. Additional Integral Item}

An integral item of output voltage error is added to the PWM-based SMC. The new control diagram is shown in Fig 7. The red part is the integral item to eliminate static output voltage error.

With the additional integral item, a new duty cycle is shown in (17). From Equation (17), the duty cycle will always be regulated until the static error is eliminated. Meanwhile,

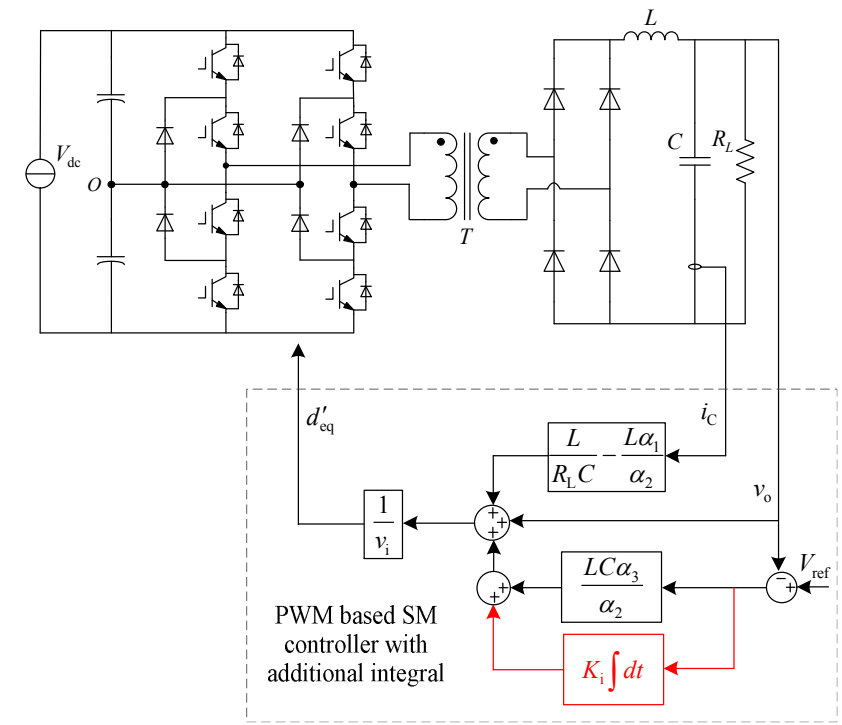

Fig. 7. PWM-based SMC with additional integral for three-level full-bridge DC-DC converter.

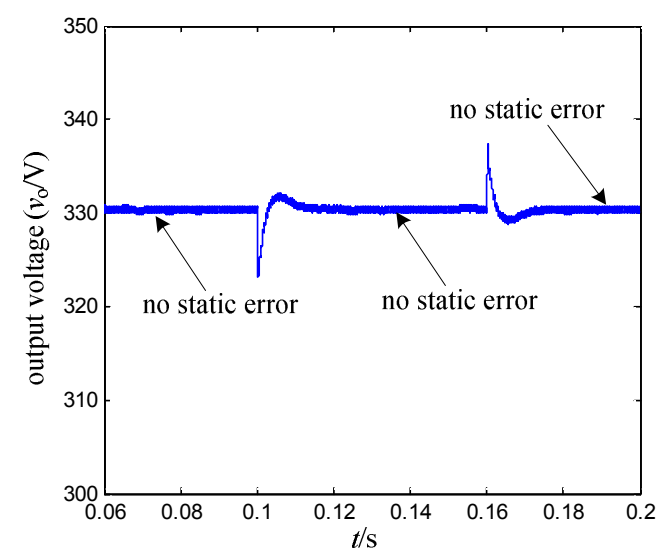

Fig. 8. Static error of PWM-based SMC with integral under load step up and load step down obtained by simulation.

integral coefficient $K_{\mathrm{i}}$ determines the speed of eliminating static error.

$$
\begin{gathered}
d_{\mathrm{eq}}^{\prime}=\frac{L}{v_{\mathrm{i}}}\left(\frac{1}{R_{\mathrm{L}} C}-\frac{\alpha_{1}}{\alpha_{2}}\right) i_{\mathrm{C}}+\frac{\alpha_{3} L C}{\alpha_{2} v_{\mathrm{i}}}\left(V_{\text {ref }}-v_{\mathrm{o}}\right) \\
+\frac{v_{\mathrm{o}}}{v_{\mathrm{i}}}+\frac{K_{\mathrm{i}}}{v_{\mathrm{i}}} \int\left(V_{\text {ref }}-v_{\mathrm{o}}\right) d t
\end{gathered}
$$

Fig. 8 shows the static error of PWM-based SMC with an additional integral under load step up and load step down obtained by simulation. The desired output DC voltage is 330 Vdc. In Fig. 8, the load before $0.1 \mathrm{~s}$ and after $0.16 \mathrm{~s}$ is 8 $\Omega$, and the load between $0.1 \mathrm{~s}$ and $0.16 \mathrm{~s}$ is $4 \Omega$. Moreover, no static output voltage error is observed all the time under different loads. The integral coefficient $K_{\mathrm{i}}$ is also equal to 100.

The dynamic performance of PWM-based SMC with an additional integral under load step up obtained by simulation is shown in Fig. 9. The three waveforms are obtained through 


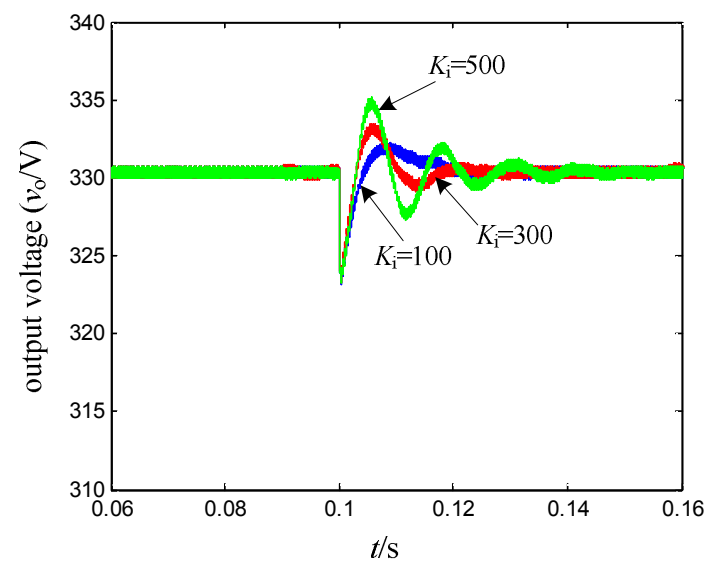

Fig. 9. Dynamic performance of PWM-based SMC with additional integral under load step up obtained by simulation.

three different integral coefficients. The integral eliminates the static error and simultaneously accelerates the dynamic response speed. When the integral coefficient is too large, the output voltage waveform overshoots and chattering may occur for a short time.

The whole system diagram of PWM-based SMC with an additional integral for three-level full-bridge DC-DC converter is shown in Fig. 10.

The double loop PI controller can also eliminate static output error. However, PWM-based SMC in this paper is different from the PI controller. First, a double loop PI controller is designed based on a small signal model at a specific operation point. PI parameters are usually designed through a bode plot of the system. Double loop PI controller is a linear controller. PWM-based SMC is designed based on the trajectory of the state variable at a full range of load. SMC parameters are designed through a sliding surface. PWM-based SMC is a nonlinear controller. Second, load resistor and input voltage are reflected in the SMC. With this controller, the converter can achieve better robustness than the PI controller. Third and last, the outer loop generates current reference for the inner loop in a double-loop PI controller. However, no current reference and no inner loop controller are found in PWM-based SMC proposed in this paper.

\section{B. Regulated Sliding Surface}

The equivalent control function shown in Equation (16) is obtained from the trajectory of state variable, as shown in Equation (7). Sliding surface of the hysteretic SMC is $S=0$. Adding an item in an equivalent control function means that the original trajectory of state variable should be regulated to adapt to the new control function. When the trajectory of the state variable is defined as Equation (18), the control function can be obtained as Equation (17). Thus, the sliding surface for PWM-based SMC with integral is $S^{\prime}=0$.

$$
S^{\prime}=\alpha_{1} x_{1}+\alpha_{2} x_{2}+\alpha_{3} x_{3}+\alpha_{4} x_{4}=\boldsymbol{J}^{\prime \mathrm{T}} \boldsymbol{x}^{\prime}
$$

where

$$
\begin{gathered}
\boldsymbol{J}^{\prime \mathrm{T}}=\left[\begin{array}{llll}
\alpha_{1} & \alpha_{2} & \alpha_{3} & \alpha_{4}
\end{array}\right] \\
\boldsymbol{x}^{\prime}=\left[\begin{array}{llll}
x_{1} & x_{2} & x_{3} & x_{4}
\end{array}\right]^{\mathrm{T}} \\
\alpha_{4}=\frac{K_{\mathrm{i}} \alpha_{2}}{L C} \\
x_{4}=\int\left(\int\left(V_{\text {ref }}-v_{\mathrm{o}}\right) d t\right) d t
\end{gathered}
$$

A comparison of the old trajectory in Equation (7) with the new trajectory in Equation (18) shows that a double integral item is found added in the new trajectory. The original hysteretic SMC becomes a third-order system. Given that an equivalent control conversion will decrease the order of the SMC, the PWM-based SMC with an integral is a second-order controller. This design is the fundamental reason this controller can eliminate static error.

\section{Regulated Existence Condition}

A new state variable $x_{4}$ is introduced to eliminate static error, and the new state space function is shown in Equation (23). Given that the definition of the trajectory of state variable changes to Equation (18), the existence condition of SMC will be regulated. The direct method of Lyapunov is used to derive the new existence condition. The local reachability condition of SMC is shown in Equation (24).

$$
\dot{\boldsymbol{x}}^{\prime}=\boldsymbol{A}^{\prime} \boldsymbol{x}^{\prime}+\boldsymbol{B}^{\prime} u+\boldsymbol{D}^{\prime}
$$

where

$$
\boldsymbol{A}^{\prime}=\left[\begin{array}{cccc}
0 & 1 & 0 & 0 \\
0 & -\frac{1}{R_{\mathrm{L}} C} & 0 & 0 \\
1 & 0 & 0 & 0 \\
0 & 0 & 1 & 0
\end{array}\right] \quad \boldsymbol{B}^{\prime}=\left[\begin{array}{c}
0 \\
-\frac{v_{\mathrm{i}}}{L C} \\
0 \\
0
\end{array}\right] \quad \boldsymbol{D}^{\prime}=\left[\begin{array}{c}
0 \\
\frac{v_{\mathrm{o}}}{L C} \\
0 \\
0
\end{array}\right]
$$

The local reachability condition of Equation (24) can be written as Equation (25). The detailed condition, including sliding coefficients and integral coefficient, is shown in Equation (26).

$$
\begin{gathered}
\left\{\begin{array}{c}
\dot{S}_{S^{\prime} \rightarrow 0^{+}}^{\prime}=\boldsymbol{J}^{\prime \boldsymbol{T}} \boldsymbol{A}^{\prime} \boldsymbol{x}^{\prime}+\boldsymbol{J}^{\prime \boldsymbol{T}} \boldsymbol{B}^{\prime} u_{S \rightarrow 0^{+}}+\boldsymbol{J}^{\boldsymbol{T}} \boldsymbol{D}^{\prime}<0 \\
\dot{S}_{S^{\prime} \rightarrow 0^{-}}^{\prime}=\boldsymbol{J}^{\prime \boldsymbol{T}} \boldsymbol{A}^{\prime} \boldsymbol{x}^{\prime}+\boldsymbol{J}^{\prime \boldsymbol{T}} \boldsymbol{B}^{\prime} u_{S \rightarrow 0^{-}}+\boldsymbol{J}^{\prime \boldsymbol{T}} \boldsymbol{D}^{\prime}>0
\end{array}\right. \\
0<L\left(\frac{1}{R_{\mathrm{L}} C}-\frac{\alpha_{1}}{\alpha_{2}}\right) i_{\mathrm{C}}+\frac{\alpha_{3} L C}{\alpha_{2}}\left(V_{\mathrm{ref}}-v_{\mathrm{o}}\right) \\
+v_{\mathrm{o}}+K_{\mathrm{i}} \int\left(V_{\mathrm{ref}}-v_{\mathrm{o}}\right) d t<v_{\mathrm{i}}
\end{gathered}
$$

\section{DESIGN OF SLIDING COEFFICIENTS AND INTEGRAL COEFFICIENT}

Sliding mode coefficients determine the dynamic response performance of SMC. Dynamic response performance is reflected by function $S^{\prime}=0$, as shown in Equation (27). This 


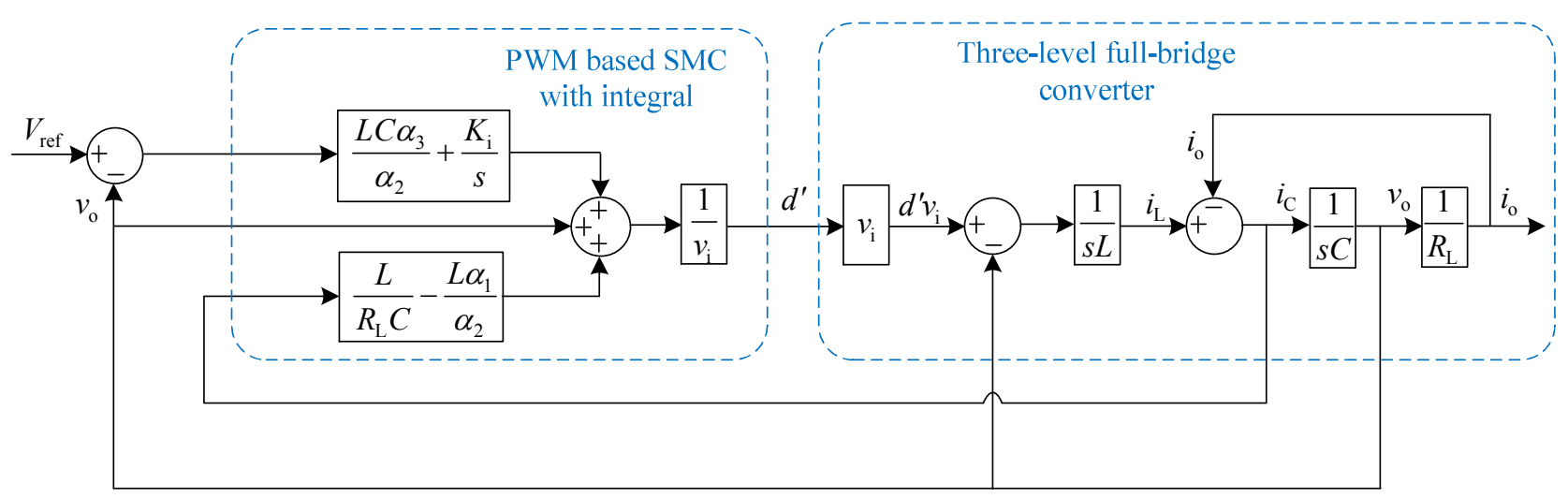

Fig. 10. Entire system diagram of PWM-based SMC with additional integral for three-level full-bridge dc-dc converter.

third-order system needs to be analyzed. The coefficient $\alpha_{4}$ represents the additional integral coefficient, as shown in Equation (21). The three sliding mode coefficients and integral coefficient are designed according to dynamic response performance of Equation (27). This design method is analyzed and used in [11].

$$
\alpha_{1} x_{1}+\alpha_{2} \frac{d x_{1}}{d t}+\alpha_{3} \int x_{1} d t+\alpha_{4} \int\left(\int x_{1} d t\right) d t=0
$$

Analysis on a third-order system is relatively complex compared with that on a second-order system. The function of integral coefficient is to eliminate the static error; its influence on the dynamic response of SMC is clearly shown in Fig. 9. Thus, the three sliding mode coefficients and the integral coefficient can be designed for PWM-based SMC with an additional integral. The three sliding mode coefficients mainly determine the dynamic response, and the integral coefficient mainly eliminates the static error.

\section{A. Design of the Three Sliding Mode Coefficients}

Dynamic response of the SMC is reflected by Equation (28). Through time differential of Equation (28), a standard second-order system can be obtained, as shown in Equation (29). In Equation (29), $\omega_{n}$ represents the undamped natural frequency and $\zeta$ represents the damping ratio. This standard second-order system has three types of responses: under damped $(0 \leq \zeta<1)$, critically damped $(\zeta=1)$, and over damped $(\zeta>1)$.

$$
\begin{gathered}
\alpha_{1} x_{1}+\alpha_{2} \frac{d x_{1}}{d t}+\alpha_{3} \int x_{1} d t=0 \\
\ddot{x}_{1}+2 \zeta \omega_{n} \dot{x}_{1}+\omega_{n}^{2} x_{1}=0
\end{gathered}
$$

where

$$
\omega_{n}=\sqrt{\frac{\alpha_{3}}{\alpha_{2}}}, \quad \zeta=\frac{\alpha_{1}}{2 \sqrt{\alpha_{2} \alpha_{3}}}
$$

First, time constant $\tau$ for this converter should be determined. Time constant represents the speed of controller dynamic response. This time constant should be selected according to power rating and switching frequency. This phenomenon is an inherent characteristic of power converter.

When the damping ratio $0 \leq \zeta \leq 1$, the time constant is shown as Equation (30), expressed by damping ratio, and undamped natural frequency. The sliding mode coefficients can be obtained through Equations (29) and (30) and shown as Equations (31) and (32).

$$
\begin{gathered}
\tau=\frac{1}{\zeta \omega_{\mathrm{n}}}=2 \frac{\alpha_{2}}{\alpha_{1}} \\
\frac{\alpha_{1}}{\alpha_{2}}=\frac{2}{\tau} \\
\frac{\alpha_{3}}{\alpha_{2}}=\frac{1}{\tau^{2} \zeta^{2}}
\end{gathered}
$$

When the damping ratio $\zeta>1$, the time constant is shown as Equation (33), expressed by damping ratio and undamped natural frequency. The sliding mode coefficients can be obtained through Equations (29) and (33) and are shown as Equations (34) and (35).

$$
\begin{gathered}
\tau=\frac{1}{\left(\zeta-\sqrt{\zeta^{2}-1}\right) \omega_{\mathrm{n}}} \\
\frac{\alpha_{1}}{\alpha_{2}}=\frac{2}{\tau\left(1-\sqrt{1-1 / \zeta^{2}}\right)} \\
\frac{\alpha_{3}}{\alpha_{2}}=\frac{1}{\tau^{2}\left(\zeta-\sqrt{\zeta^{2}-1}\right)}
\end{gathered}
$$

\section{B. Design of the Integral Coefficient}

If response speed is disregarded, then a very small integral coefficient will be able to eliminate static error. Thus, selecting a small integral coefficient is a simple, direct, and advisable design method. This coefficient also accelerates the response speed. Fig. 11 shows a typical waveform of SMC under load step up. In the figure, the area $S_{\mathrm{d}}$ represents the integral of output voltage error.

A comparison of two equivalent duty cycle functions, 


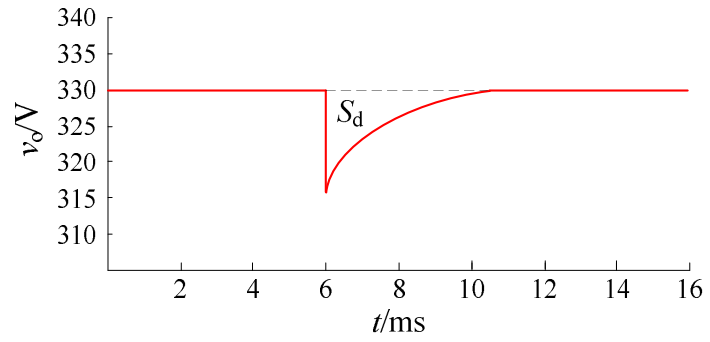

Fig. 11. Typical waveform of SMC under load step up.

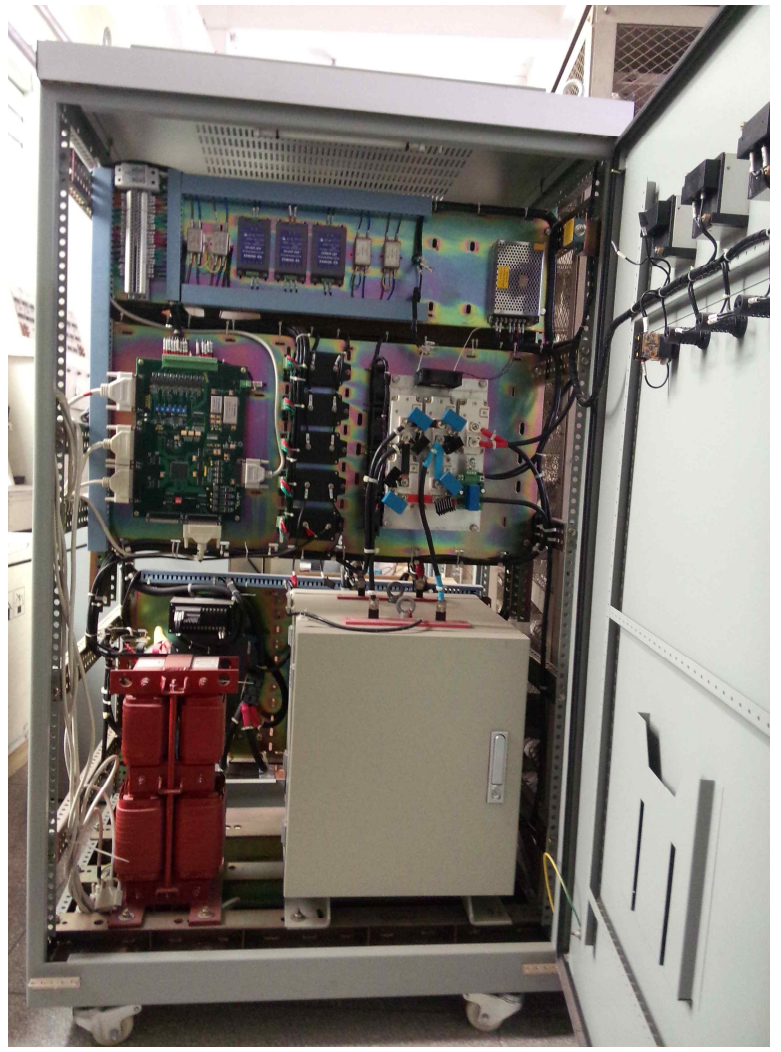

Fig. 12. Three-level full-bridge converter device.

Equations (16) and (17), shows that the latter owns an extra item $\Delta d$. This extra item is shown in Equation (36).

$$
\begin{gathered}
\Delta d=\frac{K_{\mathrm{i}}}{v_{\mathrm{i}}} \int\left(V_{\text {ref }}-v_{\mathrm{o}}\right) d t \\
\Delta d=\frac{K_{\mathrm{i}} S_{\mathrm{d}}}{v_{\mathrm{i}}}
\end{gathered}
$$

Equation (37) represents the desired duty cycle difference between PWW-based SMC and PWM-based SMC with integral. The integral coefficient can be obtained from Equation (37)

\section{EXPERIMENTAL RESULTS}

Fig. 12 shows the three-level full-bridge converter device. This device is designed for possible use on a ship's power supply system. It is used to connect a high DC voltage bus and
TABLE I

Parameters of the Three-Level Full-Bridge CONVERTER

\begin{tabular}{lc}
\hline Input voltage $\left(V_{\mathrm{dc}}\right)$ & $1000 \mathrm{Vdc}$ \\
Output voltage $\left(v_{\mathrm{o}}\right)$ & $330 \mathrm{Vdc}$ \\
Transformer ratio $\left(n_{\mathrm{T}}\right)$ & $2: 1$ \\
Switching frequency $\left(f_{\mathrm{s}}\right)$ & $3.6 \mathrm{kHz}$ \\
Filter inductor $\left(L_{\mathrm{f}}\right)$ & $3 \mathrm{mH}$ \\
Filter capacitor $\left(C_{\mathrm{f}}\right)$ & $760 \mu \mathrm{F}$ \\
Sliding coefficient one $\left(\alpha_{1}\right)$ & 833 \\
Sliding coefficient two $\left(\alpha_{2}\right)$ & 1 \\
Sliding coefficient three $\left(\alpha_{3}\right)$ & $2.63 \times 10^{5}$ \\
Integral coefficient $\left(K_{\mathrm{i}}\right)$ & 100
\end{tabular}

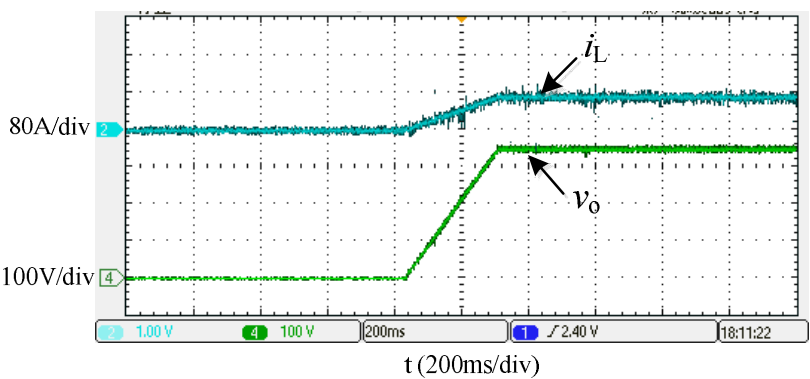

Fig. 13. Soft-start waveforms of output voltage under ramp reference condition using PWM-based SMC with integral.

a low DC voltage bus in a ship. The load is uncertain in a wide range. The converter should have precise output voltage and high-speed dynamic response with the load changing.

Input voltage is $1000 \mathrm{Vdc}$ and output voltage is $330 \mathrm{Vdc}$. The load resistor may change from $2 \Omega$ to $12 \Omega$. The PWM-based SMC proposed in this paper is used in this device to achieve high-speed dynamic response and precise output voltage. The parameters of this device and SMC are shown in Table I.

The maximum power of this device is about $50 \mathrm{~kW}$. At this power rating, IGBT is selected as the main switch instead of MOSFET. To avoid high power loss, switching frequency of the converter is selected as $3.6 \mathrm{kHz}$. The parameter value of hardware is designed according to the inductor current ripple requirement and the output voltage ripple requirement.

Fig. 13 shows the soft-start waveforms of output voltage and inductor current under ramp reference condition using PWM-based SMC with integral. This converter has a good soft-start performance (Fig. 13). Therefore, the SMC can adapt for a large range of output voltage.

Fig. 14 shows the steady-state experiment waveforms of three-level full-bridge DC-DC converter using PWM-based SMC with integral. The four waveforms are primary side current of transformer, drive signal of $Q 1$, primary side voltage of transformer, and output voltage. This converter owns good steady-state performance (Fig. 14).

Soft-start waveforms and steady state waveforms obtained by PWM-based SMC without integral are similar with those obtained by PWM-based SMC with integral, except for the 


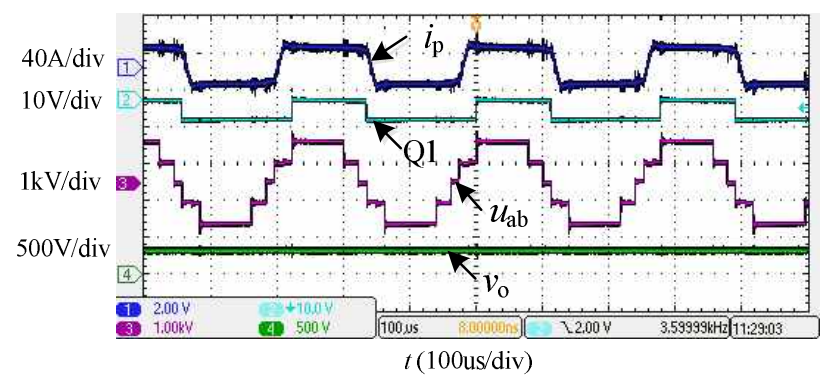

Fig. 14. Steady state experiment waveforms of three-level full-bridge converter using PWM-based SMC with integral.

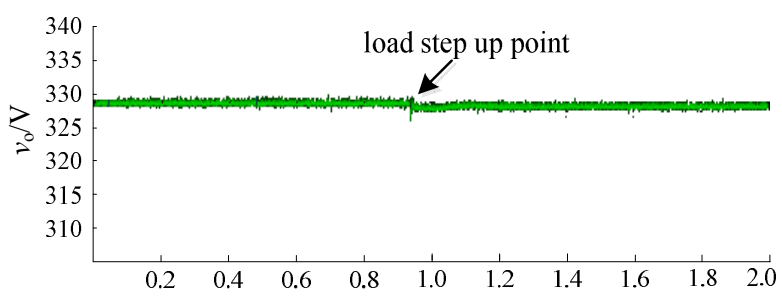

(a) $t / \mathrm{s}$

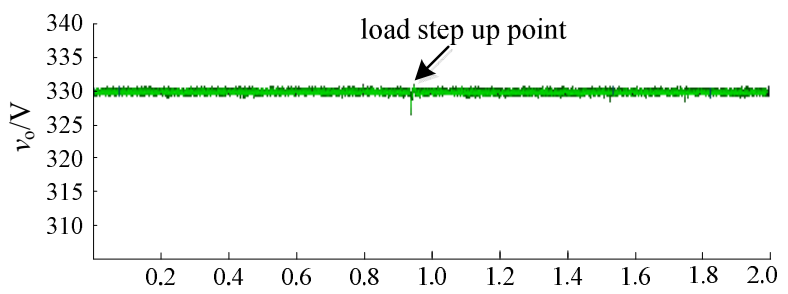

(c) $t / \mathrm{s}$

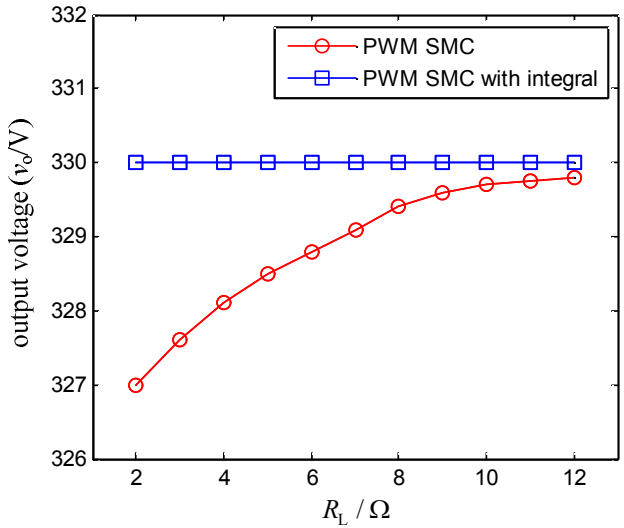

Fig. 15. Relationship curves of DC output voltage and load resistor.

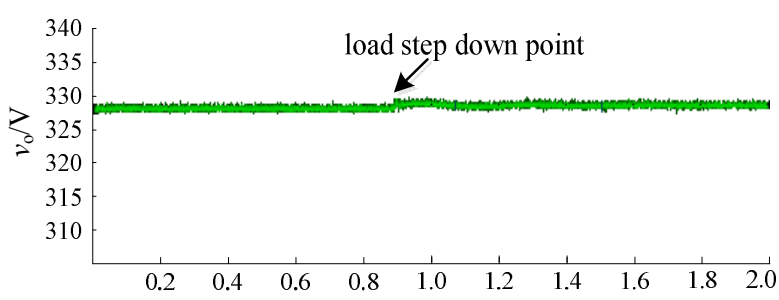

(b) $t / \mathrm{s}$

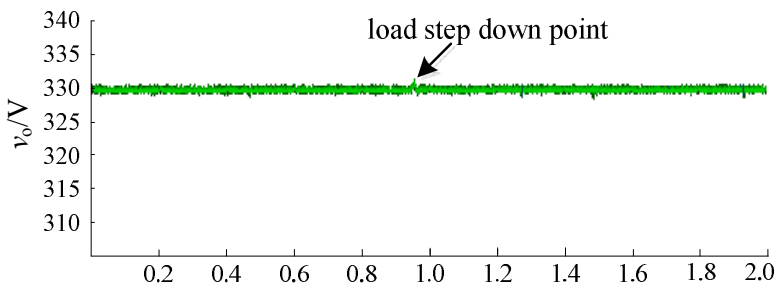

(d) $t / \mathrm{s}$

Fig. 16. Experimental waveforms of static output voltage error. (a) PWM-based SMC under load step up. (b) PWM-based SMC under load step down. (c) PWM-based SMC with integral under load step up. (d) PWM-based SMC with integral under load step down.

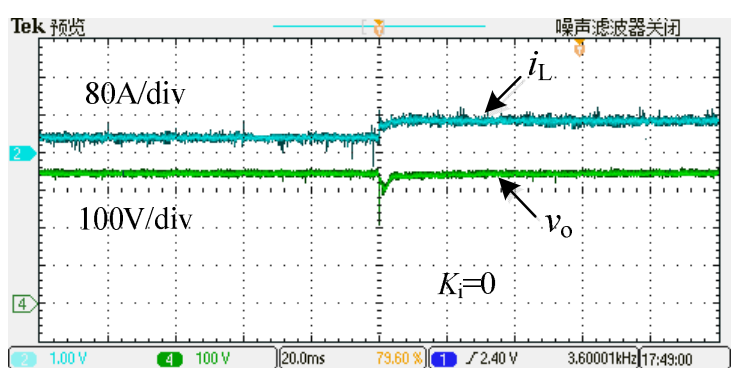

(a) $t(20 \mathrm{~ms} / \mathrm{div})$

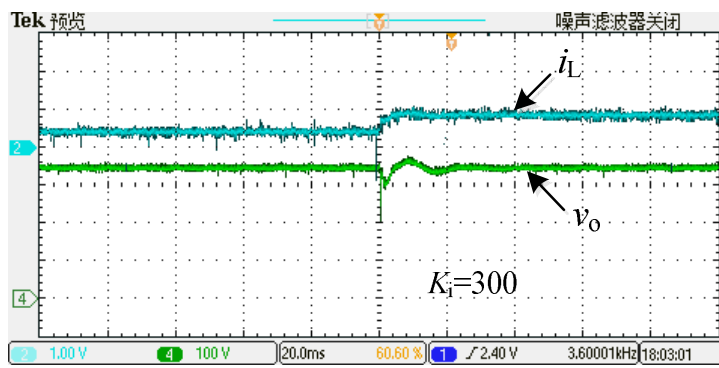

(c) $t(20 \mathrm{~ms} / \mathrm{div})$

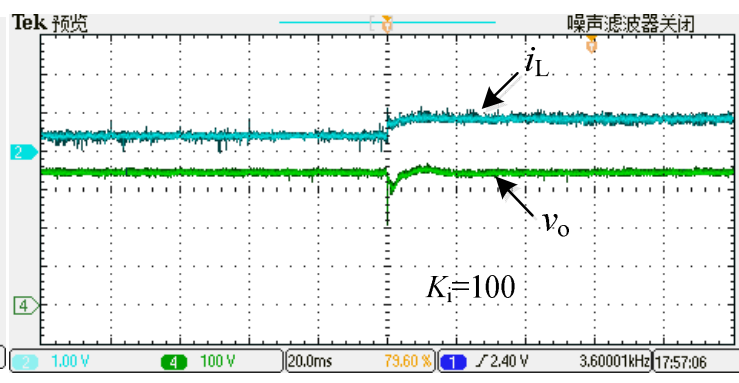

(b) $t(20 \mathrm{~ms} / \mathrm{div})$

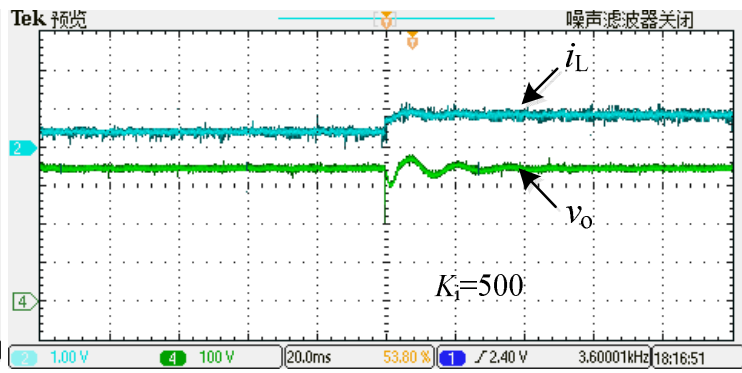

(d) $t(20 \mathrm{~ms} / \mathrm{div})$

Fig.17 Dynamic response performance of PWM-based SMC with additional integral under load step up using different integral coefficients. (a) $K_{\mathrm{i}}=0$; (b) $K_{\mathrm{i}}=100$. (c) $K_{\mathrm{i}}=300$. (d) $K_{\mathrm{i}}=500$. The load resistor changes from $8 \Omega$ to $4 \Omega$. 
static output error. The static output error is difficult to observe in Figs. 13 and 14.

Static output voltage error is measured under a series of load. Relationship curves of DC output voltage and load resistor are shown in Fig. 15. The figure indicates that a heavy load causes a large static output error using PWM-based SMC. In addition, the PWM-based SMC with integral will not cause static output voltage error.

Fig. 16 shows the detailed experimental waveforms of static output voltage error using the two controllers under load step up and load step down. In load step up condition, the load changes from $8 \Omega$ to $4 \Omega$. In load step down condition, the load change is contrary. The static output error is significant and influenced by the load [Figs. 16(a) and 16(b)]. No static error is found and static error is not influenced by the load resistor [Figs. 16(c) and 16(d)]. The advantage of PWM-based SMC with integral is significant.

Fig. 17 shows the dynamic response performance of PWM-based SMC with additional integral under load step up using different integral coefficients. The load resistor changes from $8 \Omega$ to $4 \Omega$. The integral eliminates the static error and accelerates the response speed. When $K_{\mathrm{i}}>0$, no static output voltage error is observed. Meanwhile, a large integral coefficient will cause the output voltage waveform to overshoot and chatter for a short time. The time scale in Fig. 16 is $200 \mathrm{~ms} / \mathrm{div}$, while the time scale in Fig. 17 is $20 \mathrm{~ms} / \mathrm{div}$. Thus, in the time axis, the range in Fig. 17 is only one-tenth of the range in Fig. 16. Figure 16 shows the significant static output voltage error in a large time range, and Fig. 17 shows the significant specific dynamic response in a small time range.

\section{CONCLUSION}

This paper proposes a PWM-based SMC for full-bridge DC-DC converter that can eliminate the static output voltage error. A PWM-based SMC is derived through equivalent control concept. The second-order hysteretic SMC becomes the first-order PWM-based SMC after equivalent control conversion. The first-order controller has the ability to achieve good dynamic performance. However, it has no ability to resist the static output voltage error. Thus, an integral item is added to the PWM-based SMC. The trajectory of the state variable of SMC is redefined, and the regulated existence condition is analyzed. The integral item eliminates the static error and accelerates the response speed. Experiment results on a three-level full-bridge DC-DC converter verified the control scheme and the design method proposed in this paper.

\section{ACKNOWLEDGMENT}

This project is supported by the Program for New Century Excellent Talents in the University of China (NCET-11-0871) and supported by the National Key Basic Research Program 973 Project of China (2013CB035601)

\section{REFERENCES}

[1] V. I. Utkin, "Sliding mode control design principles and applications to electric drives," IEEE Trans. Ind. Electron., Vol. 40, No. 1, pp. 23-36, Feb. 1993.

[2] S. H. Lee, Y. Joo, J. Back, J. H. Seo, and I. Choy, "Sliding mode controller for torque and pitch control of PMSG wind power systems," Journal of Power Electronics, Vol. 11, No. 3, pp. 342-349, May 2011.

[3] R. Venkataramanan, A. Sabanovic, and S. Cuk, "Sliding mode control of dc-to-dc converter," in Proc. 11th Annual Conf. of the IEEE Industrial Electronics Society (IECON), pp. 251-258, 1985.

[4] S. C. Tan, Y. M. Lai, and C. K. Tse, "General design issues of sliding mode controllers in DC-DC converters," IEEE Trans. Ind. Electron., Vol. 55, No. 3, pp. 1160-1173, Mar. 2008

[5] R. Cardim, M. C. M. Teixeira, E. Assuno, and M. R. Covacic, "Variable structure control design of switched systems with an application to a dc-dc power converter," IEEE Trans. Ind. Electron., Vol. 56, No. 9, pp. 3505-3513, Sep. 2009

[6] S. C. Tan, Y. M. Lai, M. K. H. Cheung, and C. K. Tse, "On the practical design of a sliding mode voltage controlled buck converter," IEEE Trans. Power Electron., Vol. 20, No. 2, pp. 425-437, Mar. 2005.

[7] Y. Chen and Y. Kang, "The variable-bandwidth hysteresis modulation sliding-mode control for the PWM-PFM converters," IEEE Trans. Power Electron., Vol. 26, No. 10, pp. 2727-2734, Oct. 2011.

[8] B. R. Lin and C. C. Chen, "New three-level PWM DC/DC converter - analysis, design and experiments," Journal of Power Electronics, Vol. 14, No. 1, pp. 30-39, Jan. 2014.

[9] Y. Shi and X. Yang, "Zero-voltage switching PWM three-level full-bridge DC-DC converter with wide ZVS load range," IEEE Trans. Power Electron., Vol. 28, No. 10, pp. 4511-4524, Oct. 2013.

[10] S. C. Tan, Y. M. Lai, C. K. Tse and M. K. H. Cheung, "A fixed-frequency pulsewidth modulation based quasi sliding mode controller for buck converters," IEEE Trans. Power Electron., Vol. 20, No. 6, pp. 1379-1392, Nov. 2005.

[11] J. Ackermann and V. Utkin, "Sliding mode control design based on Ackermann's formula," IEEE Trans. Autom. Control, Vol. 43, No. 2, pp. 234-237, Feb. 1998.

[12] H. Sira-Ramirez, "A geometric approach to pulse-width modulated control in nonlinear dynamical systems," IEEE Trans. Autom. Control, Vol. 34, No. 2, pp. 184-187, Feb. 1989.

[13] S. C. Tan, Y. M. Lai, and C. K. Tse, "Indirect sliding mode control of power converters via double integral sliding surface," IEEE Trans. Power Electron., Vol. 23, No. 2, pp. 600-611, Mar. 2008

[14] C. Zhang, J. Wang, S. Li, B. Wu and C. Qian, "Robust control for PWM-based DC-DC buck power converters with uncertainty via sampled-data output feedback," IEEE Trans. Power Electron., Vol. 30, No. 1, pp. 504-515, Jan. 2015.

[15] X. Hao, X. Yang, T. Liu, L. Huang and W. Chen, "A sliding-mode controller with multi resonant sliding surface for single-phase grid-connected VSI with an LCL filter," IEEE Trans. Power Electron., Vol. 28, No. 5, pp. 2259-2268, May 2013.

[16] R. Guzman, L. G. Vicuna, A. Camacho, J. Matas, M. Castilla and J. Miret, "Active damping control for a three phase grid-connected inverter using sliding mode control," 
in Proc. 39th Annual Conference of the IEEE Industrial Electronics Society (IECON), pp. 382-387, 2013.

[17] M. Comanescu and L. Xu, "Sliding-mode MRAS speed estimators for sensorless vector control of induction machine," IEEE Trans. Ind. Electron., Vol. 53, No. 1, pp. 146-153, Feb. 2006.

[18] N. Jin, X. Wang, and X. Wu, "Current sliding mode control with a load sliding mode observer for permanent magnet synchronous machines," Journal of Power Electronics, Vol. 14, No. 1, pp. 105-114, Jan. 2014.

[19] S. Janardhanan and B. Bandyopadhyay, "Output feedback sliding-mode control for uncertain systems using fast output sampling technique," IEEE Trans. Ind. Electron., Vol. 53, No. 5, pp. 1677-1682, Oct. 2006.

[20] M. J. Jafarian and J. Nazarzadeh, "Minimum time regulation of DC-DC converters in damping mode with an optimal adjusted sliding mode controller," Journal of Power Electronics, Vol. 12, No. 5, pp. 769-777, Sep. 2012.

[21] Y. B. Shtessel, O. A. Raznopolov, and L. A. Ozerov, "Control of multiple modular DC-to-DC power converters in conventional and dynamic sliding surfaces," IEEE Trans. Circuits Syst. I, Fundam. Theory Appl., Vol. 45, No. 10, pp. 1091-1100, Oct. 1998.

[22] S. K. Mazumder, A. H. Nayfeh, A. Borojevic, P. Gaya, and O. López, "Robust control of parallel DC-DC buck converters by combining integral variable- structure and multiple-sliding-surface control schemes," IEEE Trans. Power Electron., Vol. 17, No. 3, pp. 428-437, May 2002.

[23] R.-J. Wai and L.-C. Shih, "Design of voltage tracking control for dc-dc boost converter via total sliding-mode technique," IEEE Trans. Ind. Electron., Vol. 58, No. 6, pp. 2502-2511, Jun. 2011.

[24] S. Oucheriah and L. Guo, "PWM-based adaptive sliding mode control for Boost DC-DC converters," IEEE Trans. Ind. Electron., Vol. 60, No. 8, pp. 3291-3294, Aug. 2013.

[25] S. Li, J. Yang, W. Chen, and X. Chen, Disturbance Observer-Based Control: Methods and Applications, CRC Press, pp. 3-17, 2014.

[26] J. Yang, S. Li, and X. Yu, "Sliding-mode control for systems with mismatched uncertainties via a disturbance observer," IEEE Trans. Ind. Electron., Vol. 60, No. 1, pp. 160-169, Jun. 2013.

[27] J. Liu, F. Xiao, W. Chen, and G. Yang, "A novel control scheme for three-level full-bridge converter achieving low THD output voltage," in Proc. 7th International Power Electronics Conference (IPEC), pp. 66-71, 2014.

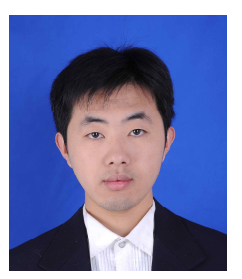

Jilong Liu was born in 1988 in Hebei Province, China. He received his B.S. degree in 2010 from the School of Electrical Engineering, Xi'an Jiaotong University, Xi'an, China. From 2010 to 2012, he worked toward the M.S. degree in Xi' an Jiaotong University. $\mathrm{He}$ is currently working toward a Ph.D. degree in Xi'an Jiaotong University. His current research interests include distributed control scheme of power electronics system and high-voltage large-capacity power electronics equipment.

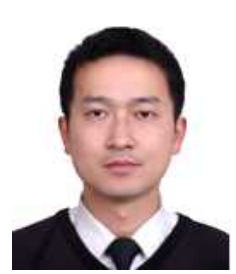

Fei Xiao was born in 1977 in Hubei Province, China. He received his B.S and M.S degrees in Electrical Engineering in 1999 and 2001, respectively, from the Naval University of Engineering, Wuhan, China. From 2003 to 2009, he was a lecturer at the Naval University of Engineering. He was promoted to an Associate Professor in 2009 and then a Full Professor in 2012. His current research interests include renewable energy generation, modeling and control of power electronics system, and high-voltage large-capacity power electronics equipment.

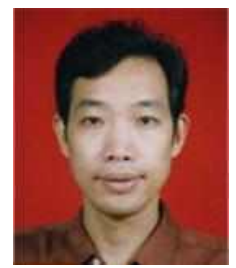

Weiming Ma was born in April 1960 in Jiangsu Province, China. He received his M.S. degree in Electrical Engineering in 1982 from the Naval University of Engineering, Wuhan, China, and his $\mathrm{PhD}$ degree in Electrical Engineering in 1996 from Tsinghua University, Beijing, China. He was elected to the Chinese Academy of Engineering and became an academician in 2001. He is currently a professor at the Naval University of Engineering and works as the Director of the National Key Laboratory for Vessel Integrated Power System Technology. He has published 2 monographs and more than 300 papers in several authoritative academic journals. He also achieved 38 national granted invention patents. Prof. Weiming $\mathrm{Ma}$ has received the following prizes: two first-class prizes in the National Science and Technology Progress Award, two third-class prizes in the National Award for Invention, and four first-class prizes in the Army Award for Science and Technology Progress.

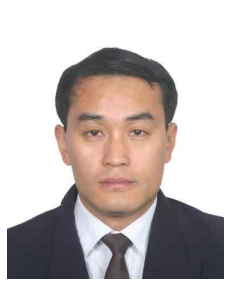

Xuexin Fan was born in 1977 in Zhejiang Province, China. He received his B.S and M.S. degrees in Electrical Engineering in 2000 and 2003, respectively, from the Naval University of Engineering, Wuhan, China. From 2003 to 2013, he was a lecturer in the Naval University of Engineering. He was promoted to an Associate Professor in 2013. His research interests include independent power system and high-voltage multi-level converters.

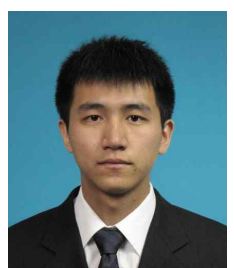

Wei Chen was born in 1989 in Jilin Province, China. He received his B.S. degree from the Department of Automation from Tsinghua University, Beijing, China, in 2012. $\mathrm{He}$ is currently working toward his M.S. degree in the Naval University of Engineering, Wuhan, China. His current research interests include modeling and control of parallel connected three-phase inverters system and large-capacity power electronics equipment. 